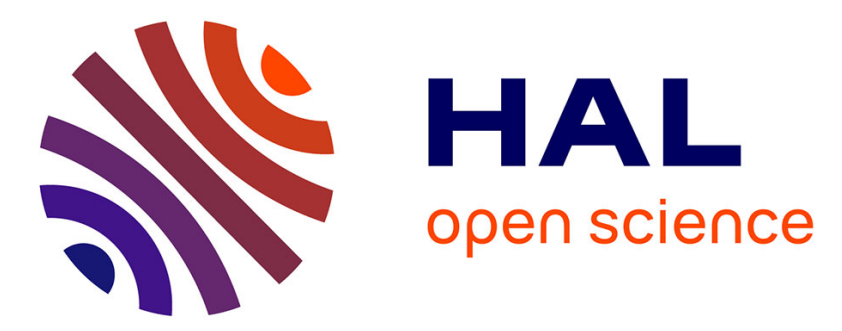

\title{
Assessing the Containment Efficiency of a Microbiological Safety Cabinet During the Simultaneous Generation of a Nanoaerosol and a Tracer Gas
}

\author{
Vincent Cesard, Emmanuel Belut, C. Prevost, A. Taniere, N. Rimbert
}

\section{- To cite this version:}

Vincent Cesard, Emmanuel Belut, C. Prevost, A. Taniere, N. Rimbert. Assessing the Containment Efficiency of a Microbiological Safety Cabinet During the Simultaneous Generation of a Nanoaerosol and a Tracer Gas. Annals of Occupational Hygiene, 2013, 57 (3), pp.345-359. 10.1093/annhyg/mes076 . hal-00824185

\section{HAL Id: hal-00824185 \\ https://hal.science/hal-00824185}

Submitted on 3 Nov 2013

HAL is a multi-disciplinary open access archive for the deposit and dissemination of scientific research documents, whether they are published or not. The documents may come from teaching and research institutions in France or abroad, or from public or private research centers.
L'archive ouverte pluridisciplinaire HAL, est destinée au dépôt et à la diffusion de documents scientifiques de niveau recherche, publiés ou non, émanant des établissements d'enseignement et de recherche français ou étrangers, des laboratoires publics ou privés. 


\title{
Assessing the containment efficiency of a microbiological safety cabinet during the simultaneous generation of a nanoaerosol and a tracer gas.
}

\author{
V. CESARD ${ }^{123^{*}}$, E. BELUT ${ }^{1}$, C. PREVOST ${ }^{2}$, A. TANIERE ${ }^{3}$ and N. RIMBERT ${ }^{3}$ \\ (1) INRS, rue du Morvan, CS 60027, 54519 Vandøuvre-lès-Nancy Cedex, France \\ (2) IRSN, BP 68, 91192 Gif-sur-Yvette Cedex, France \\ (3) LEMTA, 2 Avenue de la Forêt de Haye, BP160, 54504 Vandœuvre-lès-Nancy, \\ France \\ vincent.cesard@inrs.fr
}

\begin{abstract}
The intention of this paper is to compare the containment performance of a Type II Microbiological Safety Cabinet(MSC) confronted with the simultaneous generation of a saline nanoparticle aerosol and a tracer gas $\left(\mathrm{SF}_{6}\right)$. The back dissemination coefficient, defined as the ratio of the pollutant concentration measured outside the enclosure to the pollutant flow rate emitted inside the enclosure, is calculated in order to quantify the level of protection of each airborne contaminant tested for three enclosure operating configurations: an initial configuration (without perturbations), a configuration exposing a dummy in front of the enclosure (simulation of an operator) and a configuration employing the movement of a plate in front of the enclosure (simulation of human movement). Based on the results of this study, we observed that nanoparticulate and gaseous behaviours are strongly correlated, thus showing the predominance of air driven transport over particle specific behavior. The average level of protection afforded by the MSC was found systematically slightly higher for the nanoaerosol than for the gas in the studied configurations (emission properties of the source, operating conditions, measurements protocol). This improved protection efficiency can however not be considered as a warrant of protection for operators, since operating condition and ventilation parameters are still more influent on the containment than the pollutant nature (i.e. nanoaerosol or gas).
\end{abstract}

Keywords: nanoparticle transfer, fume cupboard, operator exposure 


\section{INTRODUCTION}

The handling of manufactured nanomaterials is growing very rapidly in laboratories. A nanomaterial includes at least one external dimension of between 1 and 100 nanometres or it has an internal structure or surface at the nanometer scale (European Commission, 2011). Inhalation is the main penetration pathway during human exposure to a nanostructured aerosol. Particles with a diameter of between 10 and $100 \mathrm{~nm}$ are primarily deposited in the alveolar air cells (INRS, 2009). In addition, toxicological knowledge of nanoparticles remains fragmented and scant. Different international bodies, experts in occupational risk prevention, have in recent years published guides describing good practices to be employed when handling nanoparticles (BSI, 2007; INRS, 2012; University of California Berkeley, 2007; IRSST, 2009). Among the set of recognised local ventilation systems, the use of ventilated enclosures (fume hoods, MSC, etc.) is widely mentioned in these different guides. These systems should constitute an appropriate means of protection for laboratory operations, space required by the project permitting. Currently, to be certified as being in conformity in Europe, ventilated enclosures must satisfy certain criteria laid down in Standard EN12469 relative to microbiological safety cabinets and in Standard EN14175 in the case of fume hoods. The type test described in both standards is based on the use of tracer gas or micrometric aerosol. In addition, many authors have demonstrated the influence of various parameters on the performance levels of these systems, including the air velocity in the aperture (face velocity), the presence of an operator, variations in sash openings, operator movement in front of the enclosure (Johnson \& Fletcher 1996; Tseng et al., 2007a and 2007b; Nicholson et al., 1999; Rake, 1978). Most of these studies are based on using a tracer gas and demonstrated that the containment efficiency was sensitive to experimental condition variation. The conclusions stemming from these studies have allowed the drawing up of design assistance, installation and exploitation tools for such systems (INRS, 2009; ACGIH, 2010). In variable experimental conditions (sash opening, extraction velocity, presence of obstacle), Prevost et al. (1997 and 1998) compared the dynamic containment efficiencies obtained from the same laboratory fume hood for three types of airborne contaminants: a gas (helium), and two aerosols with median mass aerodynamic diameters centred on $0.15 \mu \mathrm{m}$ 
for one, $5 \mu \mathrm{m}$ for the other. Both these studies demonstrated that tests conducted on the basis of the tracer gas technique, used to determine the containment efficiency in accordance with Standard EN14175, can no longer be considered as representative of real conditions in the case of a particulate pollutant whose size is close to a few microns. In this case, operator exposure to this type of pollutant can then be greatly underestimated. By extension, the question can be raised of whether the results obtained by tracer gas tracing could be representative of nanoparticle behaviour. Some studies have looked into the behaviour of nanoparticles during their handling in ventilated enclosures (Tsai et al., 2009a and 2009b). However, no one has been able to establish a correlation between the behaviour of nanoparticles and that of gas submitted to a dynamic containment barrier. When the size of the particles contained in an aerosol is smaller than an aerodynamic diameter in the order of microns, the effects of inertia and sedimentation become negligible. Particle transport is then subjected to the movement of gas (mean and turbulent motion) and Brownian diffusion (HervéBazin et al., 2007). In these conditions, particle behaviour becomes comparable to that of a passive gas, with the exception of certain physical phenomena like particle deposition, agglomeration/coagulation and electrostatic interactions. If it is considered that nanoparticles have a high deposition rate (Wood, 1981; Lee \& Gieseke, 1994; Lai et al., 2001; Hervé-Bazin et al, 2007), including within very high efficiency filters (G. Mouret, 2008), and that the probability of agglomeration is significant (Kim et al., 2003 et 2006; Koivisto et al., 2012), it can be predicted in theory that every type of enclosure must offer better containment efficiency for nanoparticles than for gaseous type pollutants in identical emission conditions.

In this study, an experimental system was therefore developed to identify any possible correlation between the behaviours of a nanoparticle aerosol and a gas. The device studied was a Type 2 Microbiological Safety Cabinet. The nanoparticle saline aerosol was generated by means of a nebuliser while the gas was produced from a pressurised bottle of $\mathrm{SF}_{6}$. All the measurements were taken in a cleanroom to eliminate particles naturally present in the atmosphere to the greatest possible extent. The performance of the device was assessed for each type of airborne contaminant according to three operating conditions: basic operation (absence of external perturbation), operation in the presence of an 
operator, simulated by a dummy, and finally operation with the movement of an operator in front of the enclosure, reproduced by a moving plate. The comparison between the respective concentrations observed at the emission source and at the measurement points then yielded information about the containment level afforded by the MSC.

\section{Materials and methods}

\section{The device studied: a microbiological safety cabinet}

The tests were carried out on a Type II microbiological safety cabinet. In working conditions, the pressure in the enclosure is lower than the ambient pressure, the air being extracted through slots placed on the work surface. This dynamic containment barrier is common to every type of ventilated enclosure. The specific ventilation feature of a Type II MSC is the following: only part of the air extracted in the lower section is fully extracted (30\%); the other part (70\%) is reintroduced after filtration through the upper section of the work area, and in so doing generates a descending uniform flow which offers, in addition to operator protection, protection of the product being handled (Figure 1). Its main dimensions as well as the ventilation parameters are summarised in Table 1. MSC ventilation behaviour was assessed in a previous study conducted by INRS using different measurement techniques such as omni directional anemometry (DANTEC Vivo Draught SN 126 and 127) and directional anemometry (Ahlborn FVA605-TA1), which allow an assessment of the velocity profiles in and around the system. The use of a diaphragm, a Pitot tube (DPCAL 8710 micromanometer) and the gas tracing technique allowed the air flow values to be obtained. The enclosure was equipped with two H14 class very high efficiency filters, as per Standard EN 1822-1, the first placed below the work area, the second above the working zone. This operating principle naturally produces a difference in containment depending on whether a gaseous pollutant or aerosol is used. Indeed, most of the particles produced in the enclosure will be trapped by the air outlet filter whereas part of the gas will be reintroduced into the upper part of the enclosure. To make the operation of the device similar for an aerosol and a gas, we elected to modify the operation of the MSC without however altering its ventilation properties. The changes made allow extraction of the entire flow 
extracted in the enclosure via an aperture created in the lower section (Figure 1). Alongside, the recirculation vent was blocked off and we added a new-air inlet in the upper section of the MSC. We conducted flow rate, velocity and pressure measurements at different points in the enclosure to ensure that the ventilation conditions between the two situations (before and after modification) had remained as close as possible.

\begin{tabular}{|c|c|c|c|c|c|c|c|}
\hline \multicolumn{3}{|c|}{ Usable dimensions (mm) } & \multirow{2}{*}{$\begin{array}{c}\text { Height of } \\
\text { aperture } \\
(\mathrm{mm})\end{array}$} & \multirow{2}{*}{$\begin{array}{c}\text { Flow rate } \\
\text { extracted } \\
\left(\mathrm{m}^{3} \cdot \mathrm{h}^{-1}\right)\end{array}$} & \multirow{2}{*}{$\begin{array}{l}\text { Flow rate } \\
\text { reintroduced } \\
\left(\mathrm{m}^{3} \cdot \mathrm{h}^{-1}\right)\end{array}$} & \multirow{2}{*}{$\begin{array}{c}\text { Average } \\
\text { descending } \\
\text { velocity } \\
\left(\mathrm{m} \cdot \mathrm{s}^{-1}\right)\end{array}$} & \multirow{2}{*}{$\begin{array}{l}\text { Average } \\
\text { velocity } \\
\text { in the } \\
\text { aperture } \\
\left(\mathrm{m} . \mathrm{s}^{-1}\right)\end{array}$} \\
\hline Width & height & depth & & & & & \\
\hline 1190 & 660 & 580 & 200 & 320 & 1100 & 0.405 & 0.372 \\
\hline
\end{tabular}

Table 1: Reference dimensions, velocities and flow rates of the MSC.

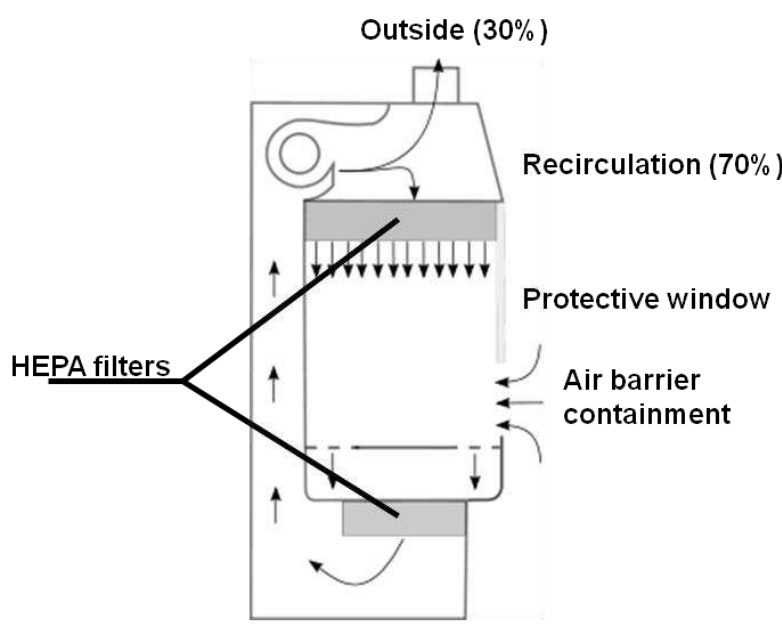

(a)

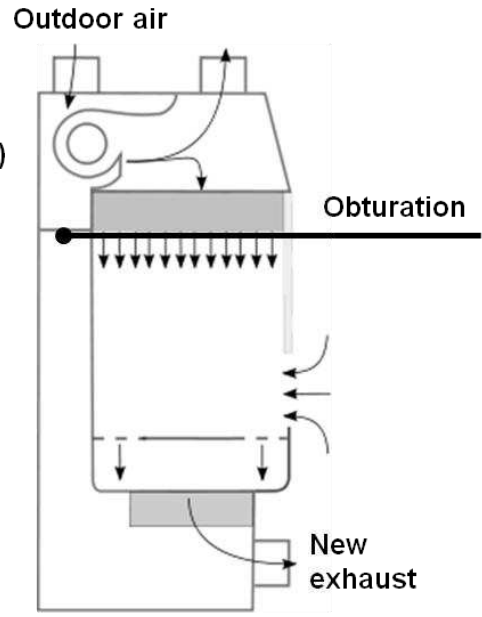

(b)

Figure 1: Operation of the MSC before modification (a) and after modification (b).

\section{Gas and nanoparticle emission}

To assess the level of protection afforded by the MSC, a nanometric aerosol as well as a tracer gas (sulphur hexafluoride $\mathrm{SF}_{6}$ ) was emitted simultaneously by means of a conical nozzle placed in the MSC enclosure (Figure 4). Firstly, the aerosol was emitted by means of a nebuliser fed by a liquid solution of distilled water and $\mathrm{NaCl}$ with a mass concentration of $0.1 \%$. The total number concentration of the dry aerosol obtained was about $10^{7}$ part. $\mathrm{cm}^{-3}$, with a median electrical mobility diameter of $50 \mathrm{~nm}$ and a geometric standard deviation of 1.7 for a air flow rate of $40 \mathrm{~L} \cdot \mathrm{min}^{-1}$, the reference flow rate for the tests presented herein. The particle size distributions (Figure 2) were evaluated using a SMPS (Scanning Mobility Particle Sizer; Cheng, 2001; Flagan, 2001) associated with a 
CNC (Condensation Nucleus Counter), the reference apparatus for measuring ultrafine aerosol concentrations. The $\mathrm{SF}_{6}$ gas was produced directly from a pressurised bottle of pure gas equipped with a mass flow meter (Bronkhorst El-Flow) to check emission flow rate. The gas and aerosol were mixed on emission by the nozzle. The average emission velocity of the mixture in the enclosure was about $0.7 \mathrm{~m} \cdot \mathrm{s}^{-1}$.

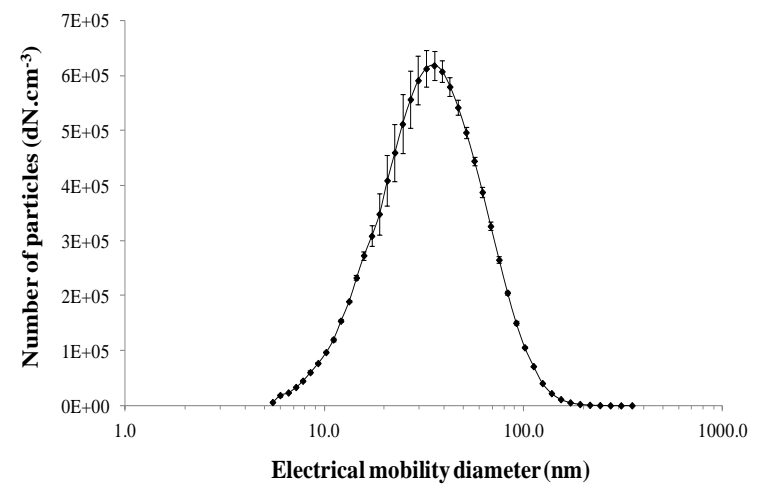

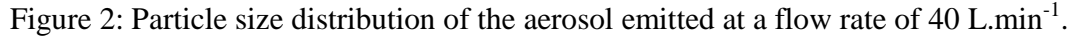

\section{The working environment}

Experimentally, very few studies have assessed the containment level afforded by different enclosures during nanoparticle handling (Tsai et al., 2009a and 2009b). As a result, the pollutant concentration levels attained outside the enclosure are unknown but potentially indiscernible from the background noise. To ensure a good signal to noise ratio, the MSC is installed inside an ISO 4 class (ISO 146441) cleanroom, meaning that less than 10,000 part. $\mathrm{m}^{-3}$ with a diameter greater than $0.1 \mu \mathrm{m}$ are detected in the room. These classifications do not cover the nanometric range, but different studies have shown that the penetration of nanoparticles through a filtering medium goes down according to their size (Skaptov et al., 1996; Heim et al., 2004; Mouret, 2008), as do the residual nanoparticle concentrations with the class of cleanroom. Dust measurements, a priori useful for checking the quality of the installation, were taken with two optical counters, the LASAIR PMS 1001 and 1002, to determine the number concentration in the median mass aerodynamic diameter range from $0.1 \mu \mathrm{m}$ to $5 \mu \mathrm{m}$. In every case, a background noise measurement was taken prior to each measurement using a SMPS + CNC (GRIMM) assembly. The usable volume of the cleanroom was $24 \mathrm{~m}^{3}$ (4 m long $\times 2 \mathrm{~m}$ wide $\times 3 \mathrm{~m}$ high) (Figure 3 ). The outdoor air was introduced through eight filter cassettes fitted with H14 filters that, in addition to filtering the air, generate a homogeneous descending air flow that sweeps the 
work piece with a velocity adjustable up to $0.3 \mathrm{~m} \cdot \mathrm{s}^{-1}$. For the requirements of the study, this velocity was set at $0.1 \mathrm{~m} . \mathrm{s}^{-1}$, a sufficiently low velocity not to perturb the operation of the system. In addition, this coincides with a renewal rate of 70 volumes per hour, a value typical of a small laboratory or a production unit.

To avoid contamination coming from outside the cleanroom, this was maintained at an overpressure of about $10 \mathrm{~Pa}$, and access was gained via an airlock kept in lower pressure that the surrounding environment (of about $50 \mathrm{~Pa}$ ).

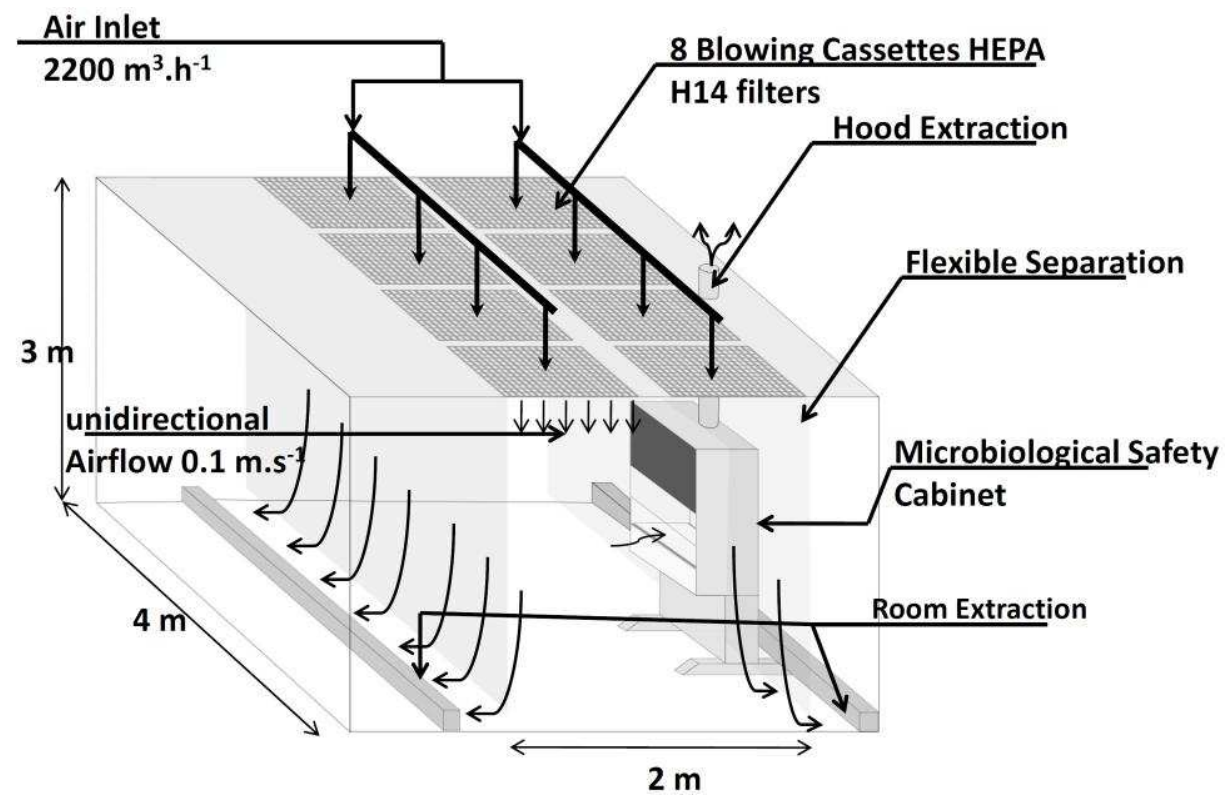

Figure 3: Schematic diagram of the complete installation.

\section{Experimental configuration}

\section{Measurement points}

Figure 4 shows the position of the 15 sampling points outside the enclosure. These points are distributed in three lines and five columns, which allows broad coverage of the aperture. Moreover, many are close to panels, where edge effects can lead to considerable differences between the behaviour of a gas and an aerosol (Prevost et al., 1998). All the sampling points are located on the same plane, $50 \mathrm{~mm}$ from the aperture. When developing these tests, we noted that a positional difference, however slight, was a source of variation in the concentrations evaluated. The aerosol and gas samples were therefore taken through the same line to avoid result bias. 


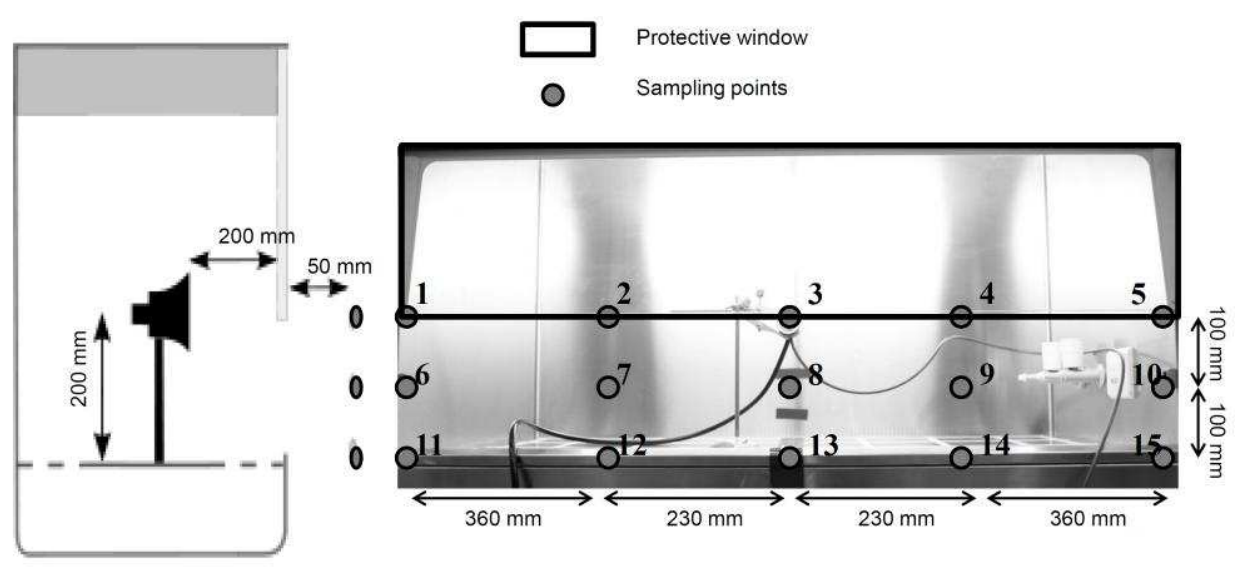

Figure 4: Distribution of the sampling points and position of the diffusion cone.

A schematic diagram of the sampling cycle is given in Figure 5. Point selection was controlled from outside the room by means of automated valves to minimise presence time in the cleanroom and thus limit perturbations (draughts, contamination, etc.). Most of the aerosol-gas mixture sampled $\left(8 \mathrm{~L} \cdot \mathrm{min}^{-1}\right.$ ) was directed to an InfraRan (Wilks Instruments) type gas analyser to obtain the $\mathrm{SF}_{6}$ gas concentration contained in the mixture. A lower proportion of the mixture $\left(0.3 \mathrm{~L}_{\mathrm{min}}{ }^{-1}\right)$ was directed to the SMPS + CNC assembly with a view to obtaining the particle size distribution and the particle number concentration in the aerosol sampled. The sampled velocity at each point is about $2.8 \mathrm{~m} . \mathrm{s}^{-1}$. The aerosol sampling line was made up of antistatic pipes/tubes and the measurement apparatus placed directly in the cleanroom to minimise sampling-duct deposit losses. There were two possible routes for the aerosol sampled; the one taken depended on the concentration level reached at each measurement point in order to determine whether to carry out or not sample dilution before measurement. The reason for such an assembly lies in the operating principle of the $\mathrm{CNC}$ that employs two counting modes: below $10^{4}$ part. $\mathrm{cm}^{-3}$, particle detection takes place in single-count mode, and beyond this value the instrument measures the particle concentration from the calibrations it has been the subject of (photometric mode). Heim et al. (2004) studied the performance of this type of apparatus and highlighted that the calibration parameters (e.g. time since last calibration and nature of aerosol used) can produce higher measurement errors than those of single-count mode. It is thus necessary that all the measurements are taken at concentrations below $10^{4}$ part.cm ${ }^{-3}$ to remain in single-count mode, which requires dilution of the sampled aerosol in certain cases.

Acquisition of all the magnitudes was carried out on a computer located in the supervision zone. 


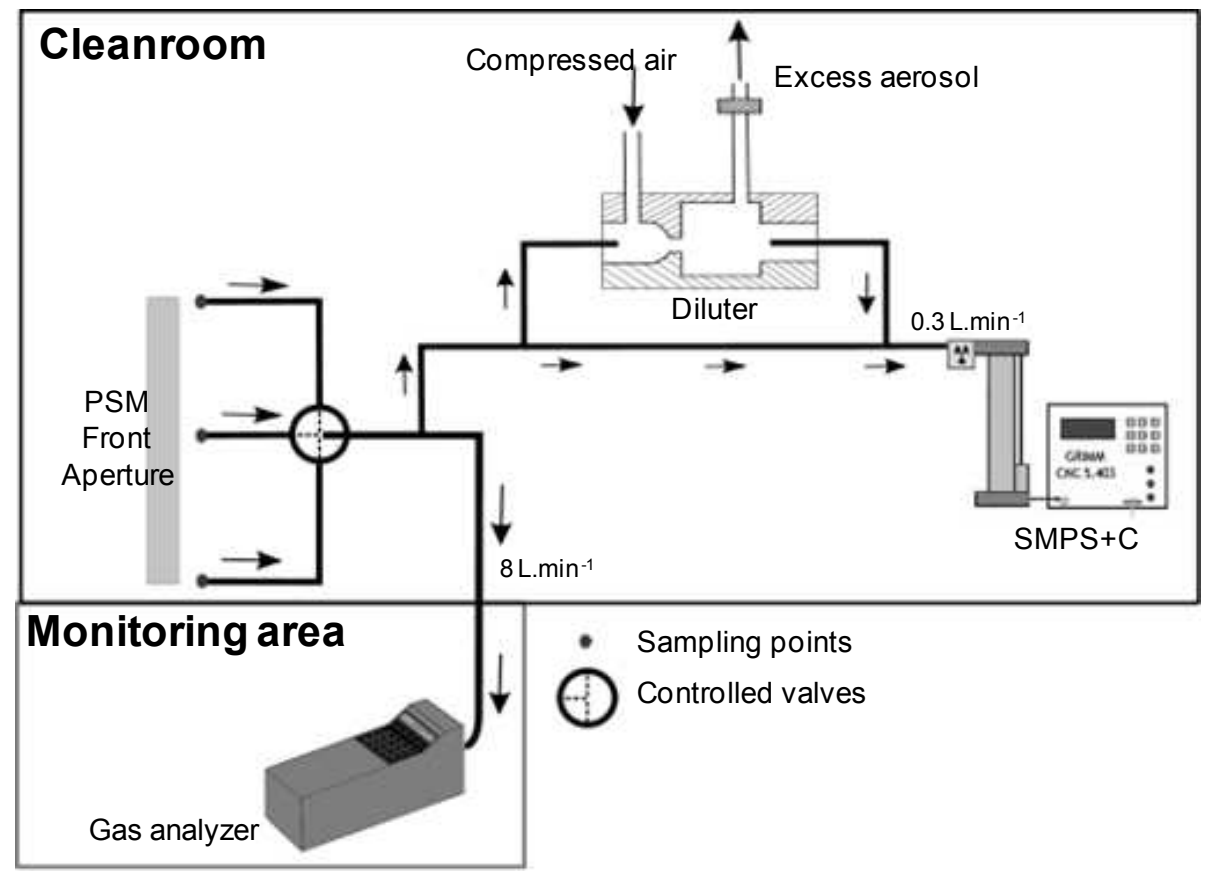

Figure 5: Schematic diagram of the gas and particulate sampling system.

\section{Measurement protocol and situations assessed}

To quantify the containment level afforded by a MSC, prior assessment of the natural ambient concentrations of the airborne contaminants undergoing test is necessary. An initial blank test of the MSC was therefore conducted, i.e. with emission of neither gas nor particles. In the case of gas, this primarily allows the detection of any possible $\mathrm{SF}_{6}$ leakage (on the extraction network) and monitoring of analyser drift ( $\mathrm{SF}_{6}$ not naturally being present in the air). For particles, the aim was to verify that the cleanroom fulfils its role, namely elimination of virtually all the particles present in the required size range $(<100 \mathrm{~nm})$, and thus quantification of the background noise of the room. Once these checks had been made, the aerosol and the gas were emitted simultaneously in the enclosure and their respective concentrations evaluated successively at each point. The experimental protocol is explained in Figure 6. In the case of particles, an additional sourceaerosol characterisation step was carried out. This was repeated twice; at the start and end of the measurement campaign. This allowed verification of the source intensity and the non-drift of the aerosol emitted. 


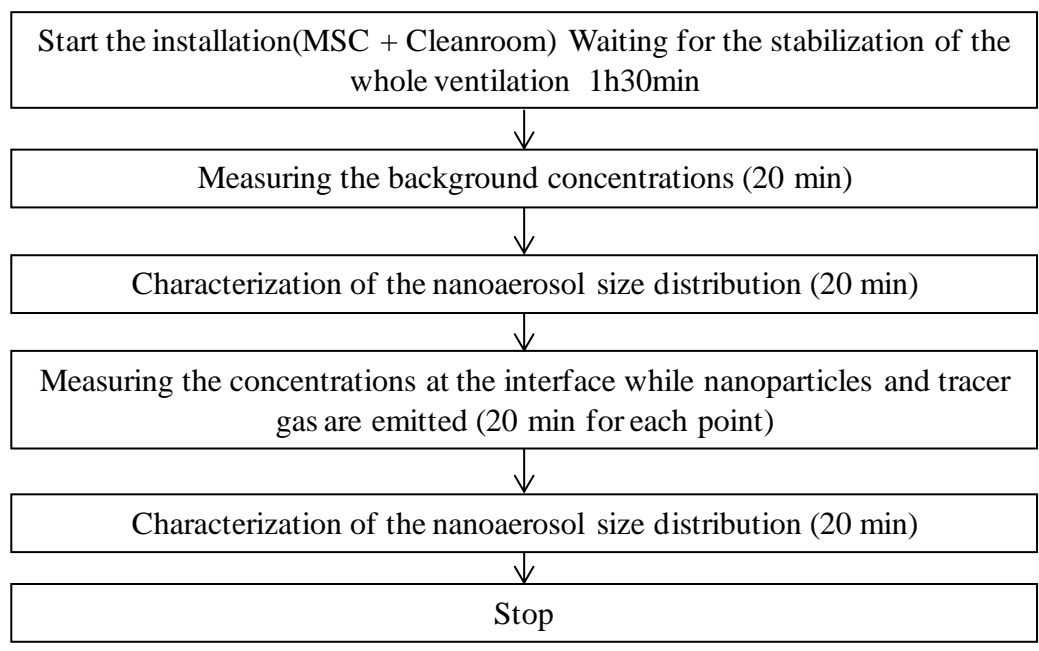

Figure 6: Experimental protocol.

The three experimental situations described earlier were then studied: the first, corresponding to normal operation, is in conformity with the description given in Figure 1. In the second case, placing the dummy in front of the enclosure is representative of someone handling a product in the ventilated enclosure, arms overreaching the containment barrier (Figure 7a). In the final situation, the $1.9 \mathrm{~m}$ high by $0.4 \mathrm{~m}$ wide plate $0.02 \mathrm{~m}$ in thickness is moved cyclically in front of the enclosure at a speed of $1 \mathrm{~m}^{-1} \mathrm{~s}^{-1}$ (test based on the standard test described in the standard relative to laboratory fume hoods, EN 14175-3; Figure 7b). The plate swings from side to side in front of the enclosure at a frequency of $0.4 \mathrm{~Hz}$, with no stoppage during the experimentation.

The experimental protocol described above was applied to each situation, one assessment lasting a full day. Each situation was assessed twice on two consecutive days to evaluate the repeatability of the test results. In parallel, temperature, pressure and humidity measurements were taken throughout the day of experimentation. 


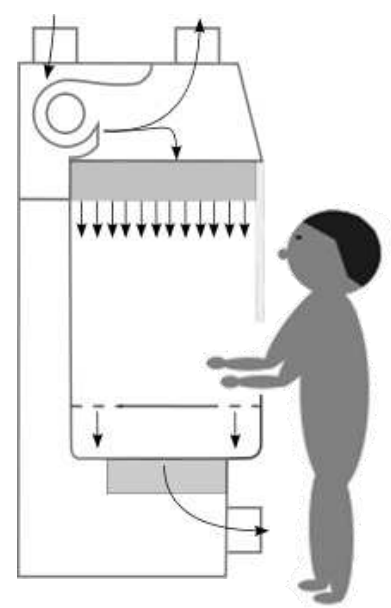

(a)

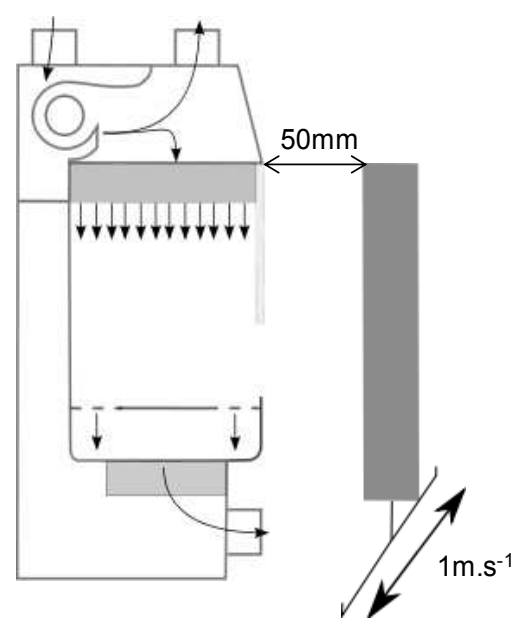

(b)

Figure 7: (a) Situation with dummy; (b) Situation with moving plate.

\section{Results}

\section{Definition of the back dissemination coefficient}

To be able to represent the dynamic containment level obtained in the different gas or nanoparticle situations, we defined the back dissemination coefficient, termed $\mathrm{K}$, as follows:

$$
\mathrm{K}=\frac{\mathrm{C}_{\mathrm{M}}^{\mathrm{B}}-\mathrm{C}_{\mathrm{M}}^{\mathrm{A}}}{\mathrm{Qs}}
$$

Equation 1

Where $\mathrm{K}$ is expressed in $\mathrm{s}^{-3} \mathrm{~m}^{-3}, \mathrm{C}_{\mathrm{M}}^{\mathrm{B}}$ is the concentration measured at a point $\mathrm{M}$ outside the enclosure in one of the situations with emission and $\mathrm{C}_{\mathrm{M}}^{\mathrm{A}}$ the concentration measured at the same point in an equivalent situation, but without emission (background noise). The particle concentrations are expressed in part. $\mathrm{m}^{-3}$ while the gas concentrations are in ppm. Qs, the flow rate associated with each source, is expressed in part. $\mathrm{s}^{-1}$ for particles and in $\mathrm{m}^{3} \cdot \mathrm{s}^{-1}$ for gas.

The lower this $\mathrm{K}$ factor, the higher the containment level achieved.

The $\mathrm{K}$ factor can easily be related to the containment factor (CF) defined in EN 14175 standard by:

$$
\mathrm{CF}=\frac{\mathrm{Qs}}{\mathrm{Qex} \cdot\left(\mathrm{C}_{\mathrm{M}}^{\mathrm{B}}-\mathrm{C}_{\mathrm{M}}^{\mathrm{A}}\right)}=\frac{1}{\mathrm{Qex} \cdot \mathrm{K}}
$$


Where Qex is the extracted flow rate expressed in $\mathrm{s}^{-3}{ }^{-3}$ (see table 1).

\section{Physical interpretation of the back dissemination coefficient}

A priori, it is not obvious to visualise what the back dissemination coefficient $\mathrm{K}$ represents physically. It is thus possible to define it as follows:

$$
\mathrm{K}=\mathrm{Q}^{-1}
$$

Equation 3

Where $Q$ is the flow rate of outdoor air to be introduced into the work premises to produce, in the presence of the source and assuming ideal flow (perfect mixture), the same level of protection as the MSC (through dilution ventilation).

\section{Measurement of the ambient operating conditions}

Temperature, relative humidity and atmospheric pressure fluctuations over the course of the test days were observed. It was noted that over the course of an evaluation day, the variation in temperature was about $4{ }^{\circ} \mathrm{C}$, relative humidity $10 \%$ and atmospheric pressure $11 \mathrm{hPa}$.

For all the tests, the residual ambient particulate concentrations was about 1 part. $\mathrm{cm}^{-3}$, even often lower, meaning that the signal detected in the configuration with emission stemmed directly from this emission.

\section{Measurement of the particulate and gaseous concentrations}

The SMPS + CNC assembly allows the particle number concentration to be obtained for a finite number of classes of diameters. The measurement range retained for the results presented here extended from $11.1 \mathrm{~nm}$ to $111.9 \mathrm{~nm}$, divided into 26 classes. The errors associated with the concentration measurements take into account the measurement uncertainty as well as the statistical dispersion corresponding to a $95 \%$ confidence interval for both concentrations. The accuracy of the SMPS $+\mathrm{C}$ measurement was evaluated at $\pm 10 \%$ of the value read (Heim et al., 2004), to which must be added the measurement accuracy of the diluter, equal to $\pm 3 \%$, when it was required. The measurement uncertainty of the analyser concerning the $\mathrm{SF}_{6}$ concentration had been assessed beforehand. This varied from $\pm 4 \%$ to $\pm 8 \%$ respectively for concentrations ranging from $9 \mathrm{ppm}$ to $0.2 \mathrm{ppm}$.

It must be pointed out that the SF6 analyser provides real time measurements, whereas only time averaged measurements are available with the SMPS+C 
assembly. Thus, gas and particle behaviours are only compared based on their time averaged concentrations. Existing fluctuations of gas concentrations with time should be correlated with particle concentration fluctuations, but the experimental apparatus cannot provide such informations.

\section{Case of the reference situation}
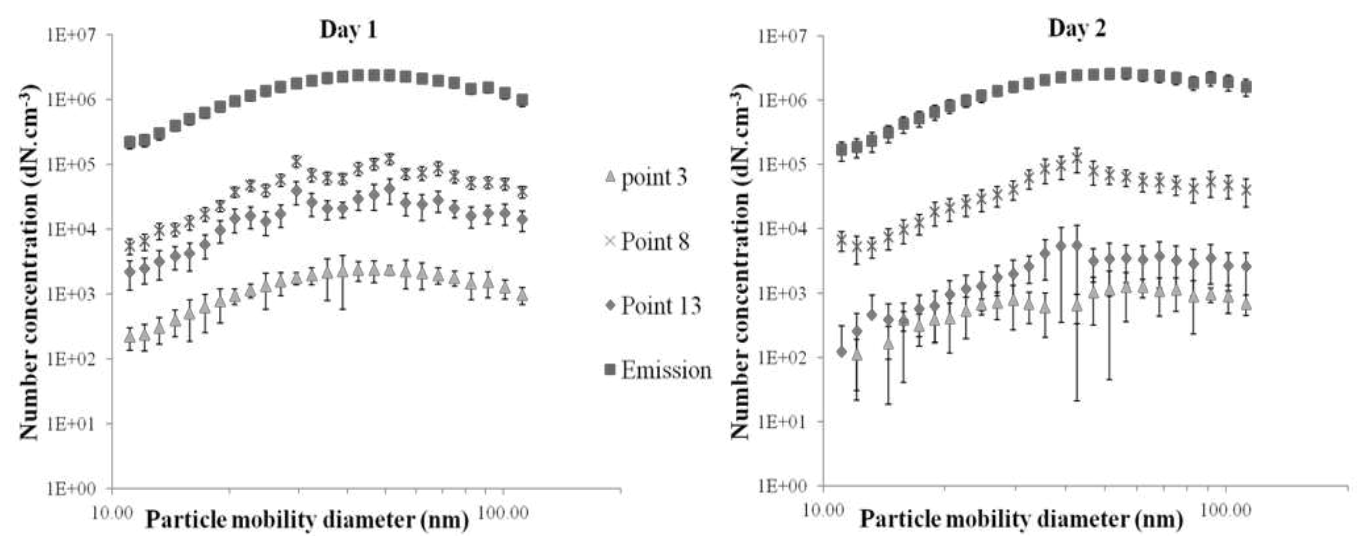

Figure 8: Particle size distributions observed at the measurement points and at emission source level for both test days in normal situation

In Figures 8 and 9, the particle number and $\mathrm{SF}_{6} \mathrm{ppm}$ concentrations observed are presented respectively for the two days of experiments in the basic situation. For the two airborne contaminants, the concentration measurements were only significant for the three points numbered 3,8 and 13 (Figure 4). They are all located along the vertical axis facing the source. The spatial distribution, in terms of relative concentration levels, was the same whether for the particulate or gaseous measurement, and was directly linked to the air flows present in the MSC, associated with the emission configuration. The highest concentration level was thus observed at point 8 , centred in relation to the height of the aperture, followed by point 13, located at the lower edge level, and finally point 3, located at the upper edge level of the aperture.
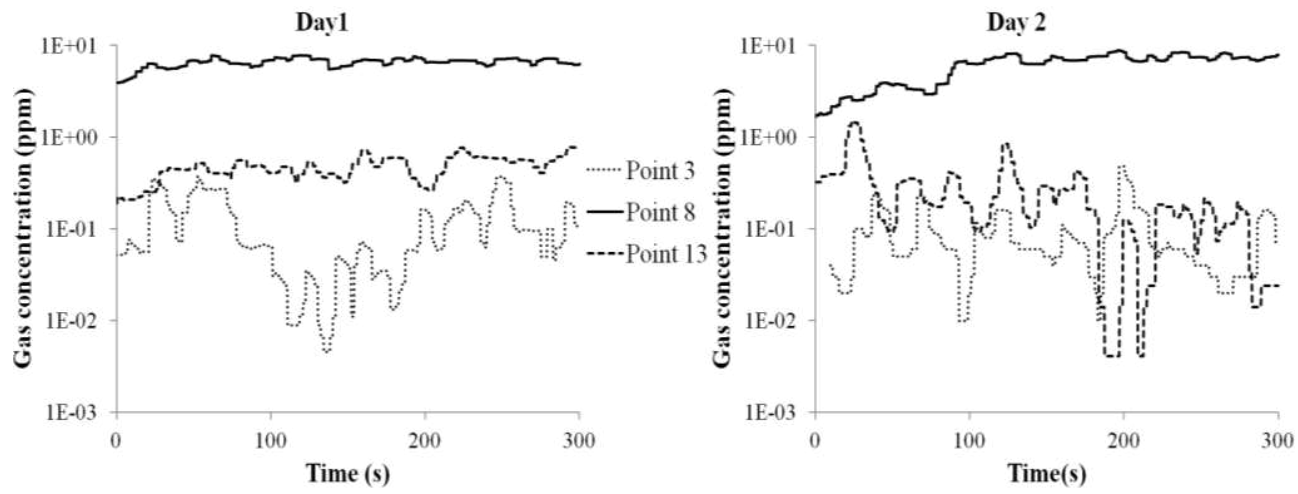
Figure 9: Evolution of the gaseous concentration with time at different points for both test days in normal situation.

The measurements taken between day 1 and 2 gave comparable results for points 3 and 8 for both types of pollutant. The values observed at point 13 presented very considerable disparities: there was a factor of 10 between the concentrations measured over the two days. In addition, the evolution of the gas concentration with time (Figure 9) for point 13 indicated the appearance of high oscillations during the second day. This temporal variability was most certainly linked to variations in the uncontrolled ventilation conditions, as they concerned both particles and gas. This disparity was again found in the situation with the dummy (Figure 11), but not in the situation with the moving plate (Figure 13), the latter being the source of strong ventilation perturbations that may have potentially masked the instabilities observed in the two other situations.

\section{Case of the situation in the presence of the dummy}
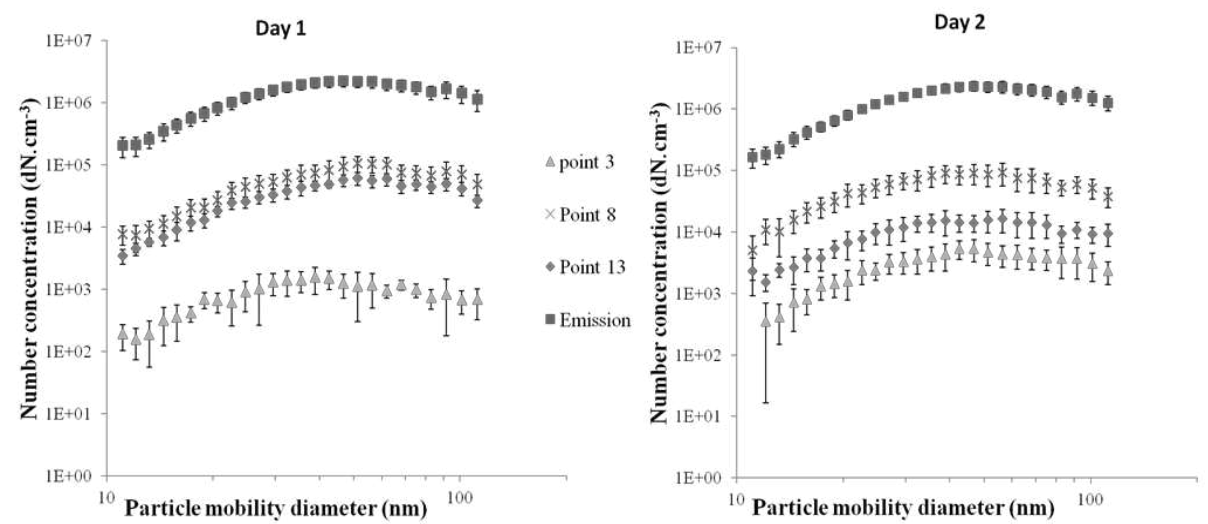

Figure 10: Particle size distributions observed at the measurement points and at emission level for both test days in the situation with the dummy.

The observations made after adding the dummy are very close to the basic situation (Figures 10 and 11). Likewise, the measurements were significant at three points (3, 8 and 13), bar that the concentration levels reached are on average greater by a factor of 1.5 . In keeping with the results obtained in many previous studies (Prévost et al., 1998; Tseng, 2006), the presence of a dummy placed at the level of the aperture of the ventilated enclosure induced modifications of the air velocity fields in and around the aperature, thus promoting transfers of the airborne contaminant out of the enclosure. 

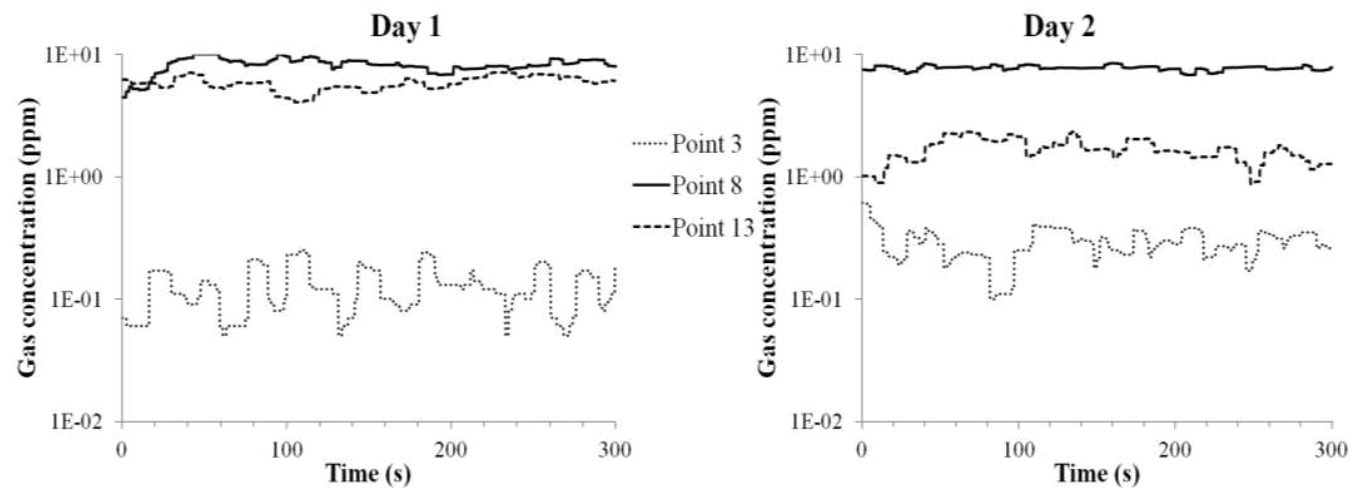

Figure 11: Evolution of the gaseous concentration with time at different points for both test days in the situation with a dummy.

As explained earlier, the concentrations observed between the $1^{\text {st }}$ and the $2^{\text {nd }}$ day were reproducible for points 3 and 8 whereas point 13 failed in terms of reproducibility. For this latter point, the average concentration levels observed between the two days varied by a factor of 6 . However, this variation concerns both the gas and the particles, allowing it to be concluded that the origin of the variation is ventilation. 

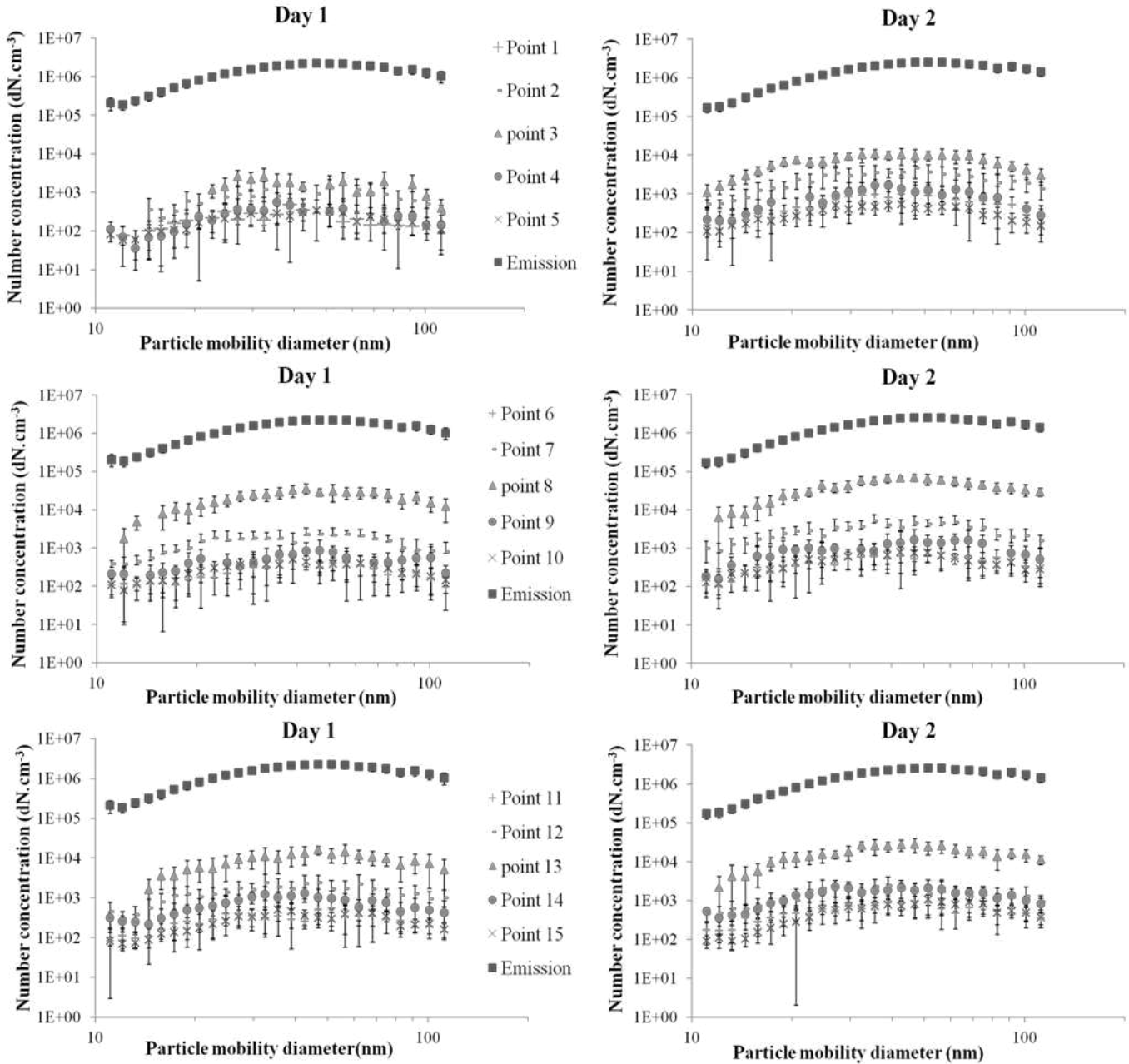

Figure 12: Particle size distributions observed at the measurement points and at the level of the emission for the two test days in the moving plate situation.

Figures 12 and 13 present the results obtained in the case of the situation employing the moving plate. For the two types of pollutants, the effect induced by the moving plate was very significant, and the concentrations measured were high over the entire mapping area studied. Put another way, the particles and the gas were highly dispersed in every direction due to the movement of the plate; the highest concentrations were always observed at points 3,8 and 13. The signal intensity detected at the other points was then directly dependent on their distance compared to these latter points. 

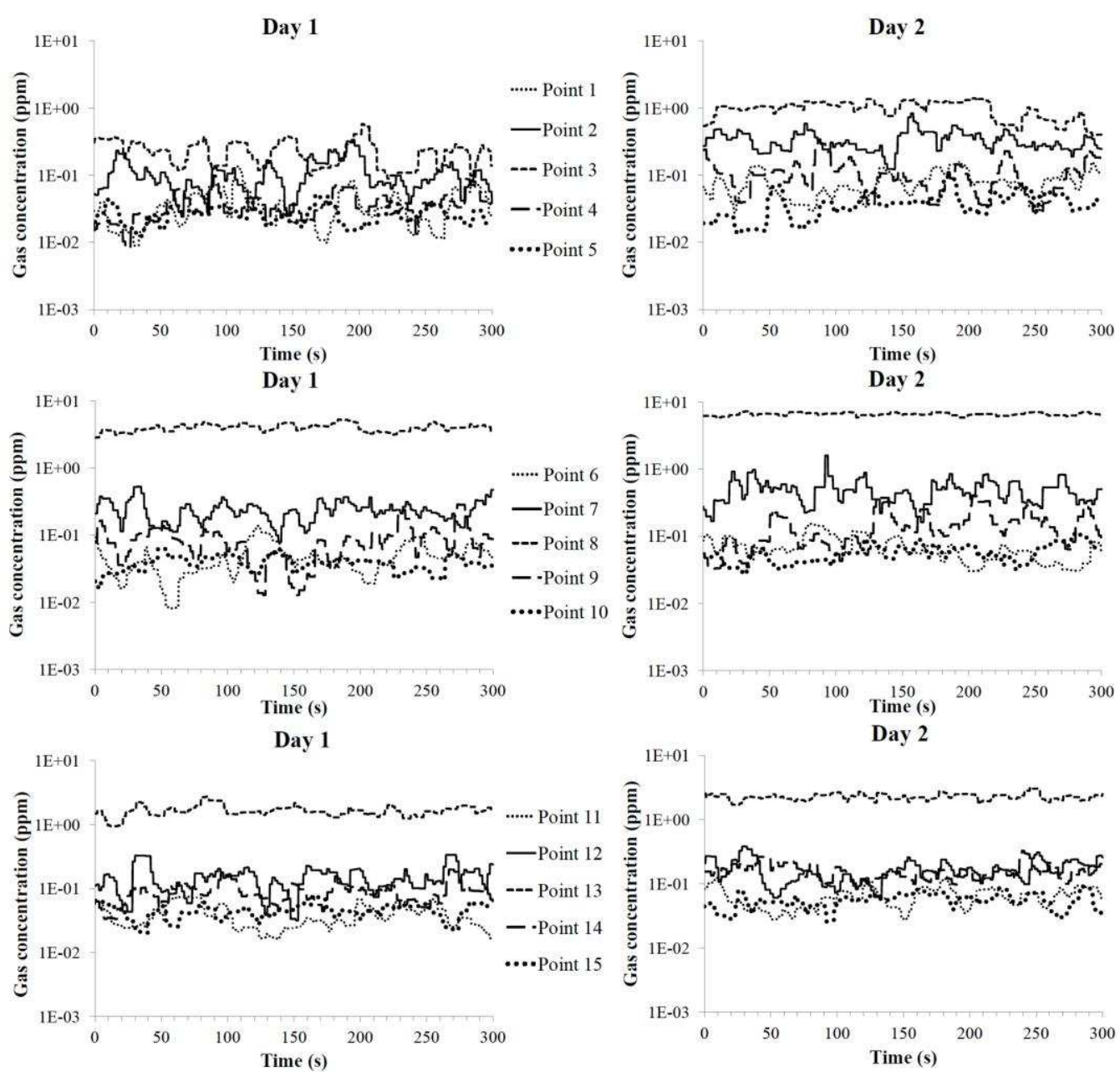

Figure 13: Evolution of the gaseous concentration with time at the different points for both test days in the moving plate situation.

\section{Calculation of the associated back dissemination coefficients}

On examining the results of Figures 8, 10 and 12, we note that, on the whole, the particle size distributions measured at each sampling point have a shape similar to the particle size distribution observed for the emission. By representing the results of these same figures in the form of a back dissemination coefficient (Equation 1) for each class of diameter, it can be observed that no back dissemination/diameter magnitude dependency appears. The back dissemination coefficients calculed below thus correspond to the back dissemination coefficients averaged on all the particles considered $(11.1 \mathrm{~nm}<\mathrm{dp}<111.9 \mathrm{~nm}$ on Figures 14 to 16$)$. 

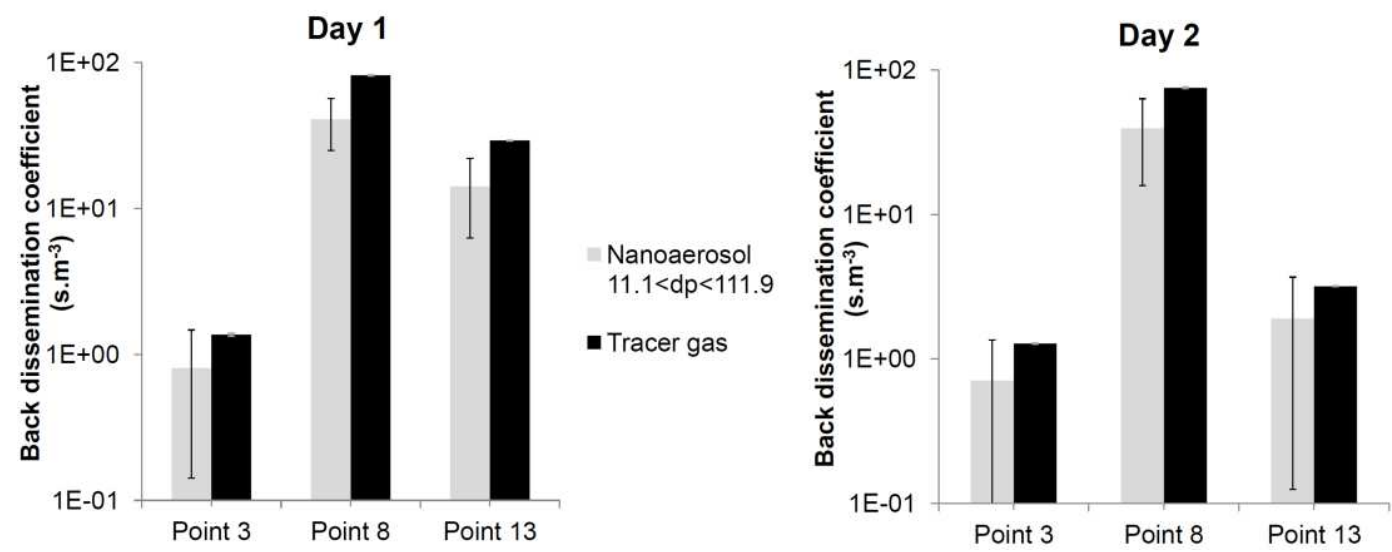

Figure 14: Comparison of the nanoparticulate and gaseous back dissemination coefficients over both assessment days for the basic situation.

Using the back dissemination coefficient as a containment level indicator allowed us to directly compare the results obtained for the nanoparticles and for the tracer gas (Figures 14, 15 and 16). As expected, nanoparticulate back dissemination was, in every case, lower than that obtained for the gas. The different situations studied as well as the large number of measurement points evaluated highlighted no specific behaviour of nanoparticles compared to that of gas.
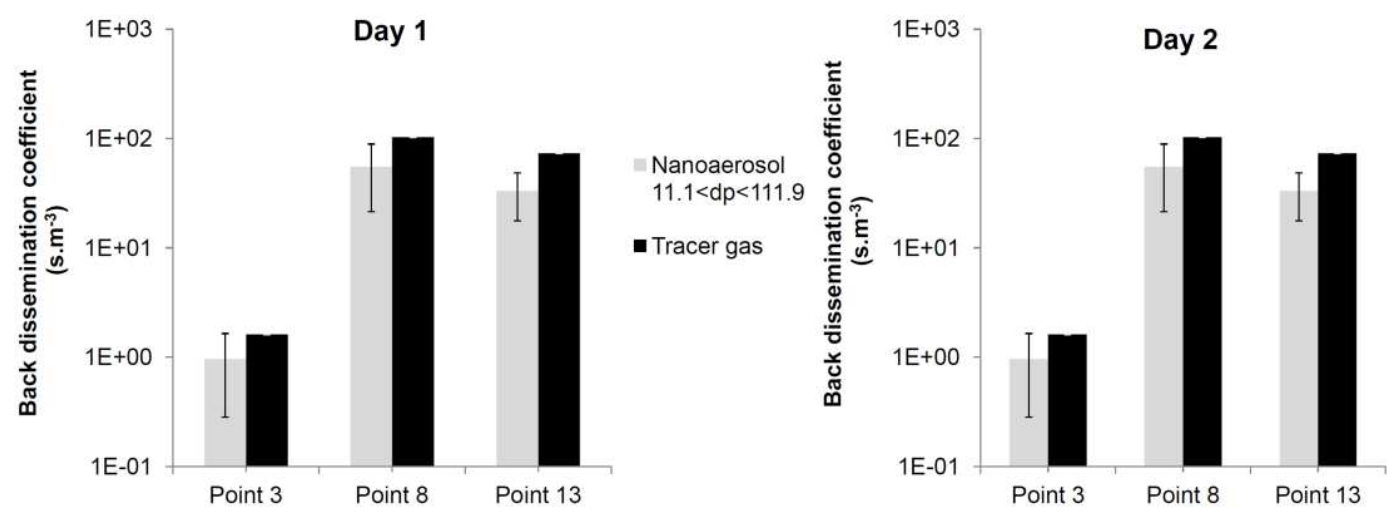

Figure 15: Comparison of the nanoparticulate and gaseous back dissemination coefficients over both assessment days for the situation withe dummy.

In Figure 16, for each measurement line, the highest back dissemination intensity is located at the central points. The back dissemination is then distributed more or less symetrically around these points, the lowest values being observed near the right and left lateral panels. The variations become very high for the off-centred points although they remain at levels comparable to those observed in the first two situations for points 3,8 and 13. This indicates that the temporal instability phenomenon created by the movement of the plate is at the origin of the spreading of the pollutant to points further from the centre. 

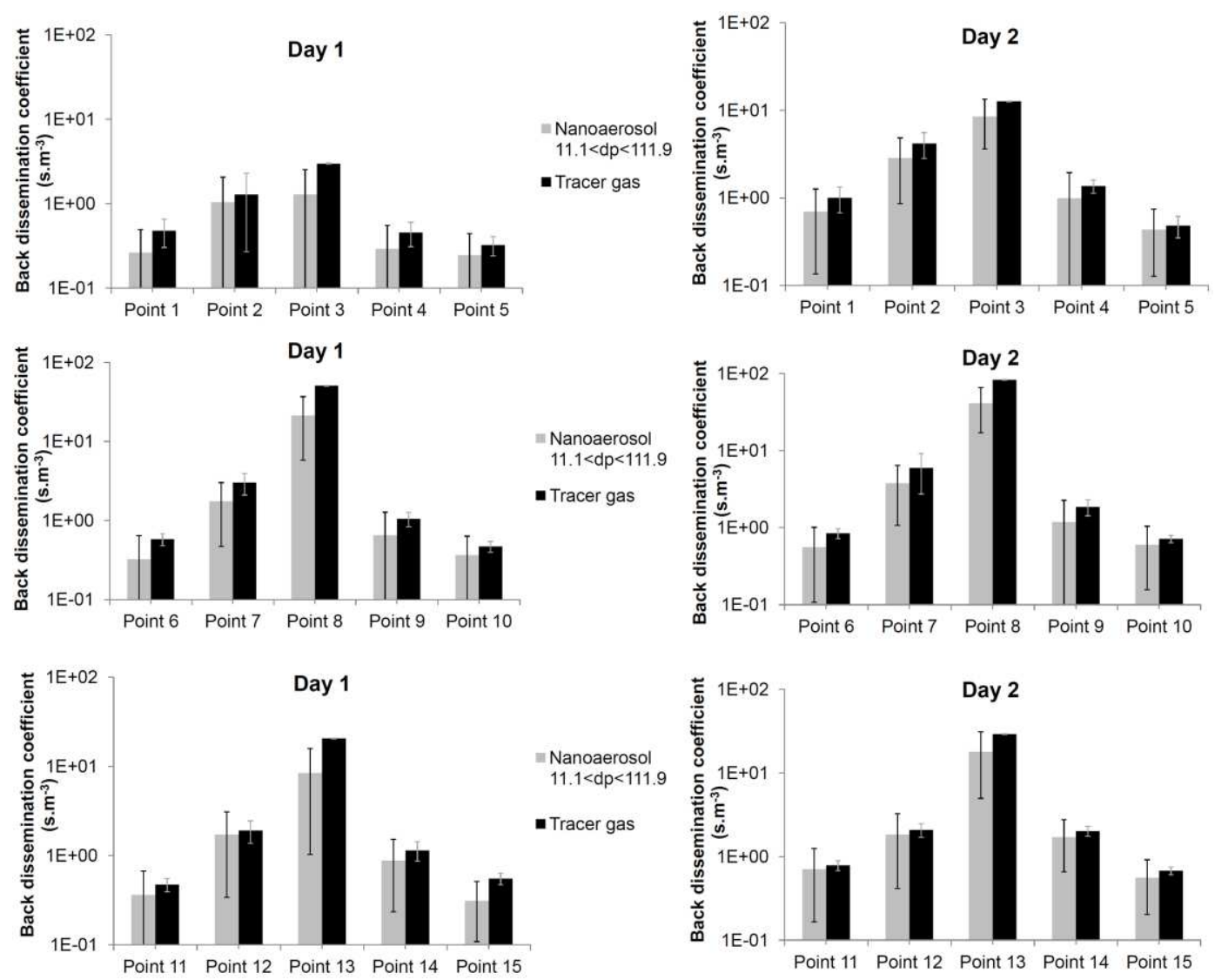

Figure 16: Comparison of the nanoparticulate and gaseous back dissemination coefficients over both assessment days for the situation with the moving plate.

This set of results allows us to represent the evolution of the nanoparticulate back dissemination coefficient as a function of the gaseous back dissemination coefficient (Figure 17). The nanoparticle back dissemination, in our case, can be expressed as a function of that obtained for the gas from a linear relationship. We thus observe that, in the experimental conditions of our study, the dynamic containment level afforded by the MSC for the nanoparticles is almost twice that for the gas $\left(\mathrm{K}_{\mathrm{nano}}=0.54 * \mathrm{~K}_{\mathrm{gas}} \pm 0.28 \mathrm{~s} . \mathrm{m}^{-3}\right)$.

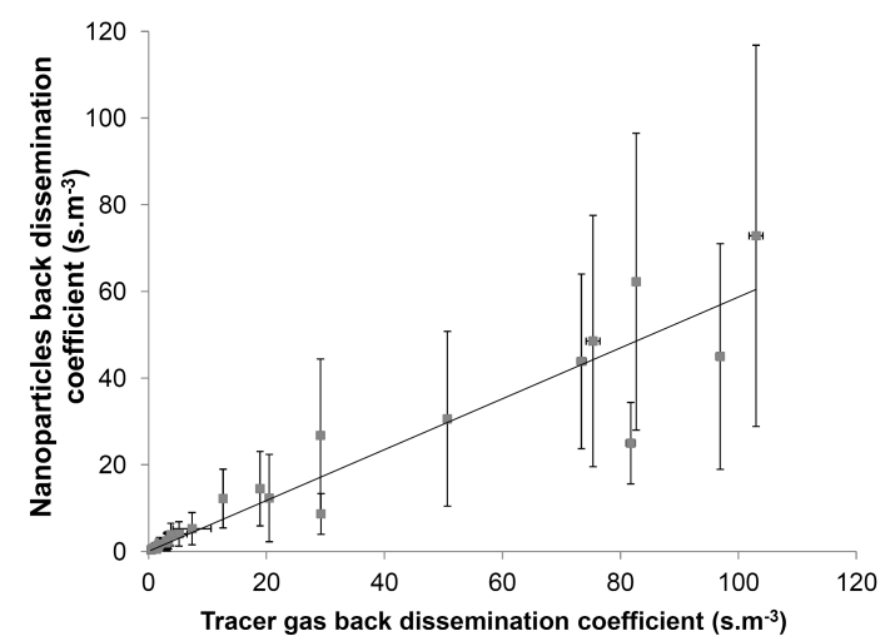

Figure 17: Correlation between particulate and gaseous back disseminations. 


\section{Conclusions}

The main aim of the study presented in this paper consisted in highlighting any specific features of nanoparticles during their transit through a containment barrier. The experimental grid employed was sized to compare the behaviour of a nanostructured aerosol with that of a tracer gas emitted simultaneously in a Type II MSC for various configurations. Thus, different technical modifications had to be made beforehand on the MSC system. Furthermore, the experimental environment, namely a cleanroom, had to be laid out to achieve a natural minimum ambient dust level in order to maximise the signal to noise ratio. The gaseous and nanoparticulate sampling points located outside the enclosure covered a large part of the aperture and its edges. Three distinct situations were studied: the first situation, termed reference, corresponds to ideal operating conditions with no external pertubations. Two more realistic operating conditions were also studied: the presence of an operator at a workstation (simulated by a dummy) and the movement of personnel in front of it (simulated by a moving plate).

The results obtained back up the hypotheses described in the introduction, namely that the containment level achieved for nanoparticles is better than for gas: the average nanoparticulate back dissemination coefficients are two times lower than those obtained for the gas, in all the situations studied.

It must however be emphasised that this result is not a gauge of operator protection, account taken of the particulate concentrations detected outside the MSC. Indeed, worthy of note is that, as of now, there are no occupational exposure limit values specifically established as a function of the particle size in question. However, based on the toxicological results obtained for nanoparticles revealing a high health risk (asbestosis for carbon nanotubes for example, Poland et al., 2008), it is envisageable that the exposure limit value should be as low as 0.1 part. $\mathrm{cm}^{-3}$ in certain cases. This value is lower by several orders of magnitude than the particulate concentrations obtained in this study and presented in Figures 8, 10 and 12. Thus, the question arises of whether this type of ventilated enclosure is capable of affording a protection adapted to the risks run insofar as the latter have been poorly assessed. It should however be noted that the emission source, chosen for the requirements of this study, is not necessarily representative of a normal operating situation of the enclosure, but rather a 
degraded situation (penalising the emission direction and velocity of the pollutants).

The comparison of the particulate and gaseous behaviours again demonstrates that the operation of a MSC, or any other comparable containment system, is very sensitive to the ambient ventilation conditions (Johnson \& Fletcher 1996; Tseng et al., 2007a and 2007b; Nicholson et al., 1999). The influence of the physicochemical properties, the intensity and the lay-out of the source, as well as the presence of an electric field, are also equally important parameters to explore to obtain a solid and complete database. In the longer term, should the results obtained confirm the very strong similarity of nanoparticulate and gaseous behaviours, a containment performance test based on emitting a tracer gas could be a reliable indicator and encompass the level of protection afforded by the system during the handling of nanoparticles.

From the prevention standpoint, this study confirms that the good practice rules, already generally defined for the use of fume hoods or other types of ventilated enclosures (INRS, 2009 and 2012), must be respected as rigourously as possible when nanoparticles whose hazardousness is unknown are handled or produced.

\section{REFERENCES}

ACGIH. (2010) Industrial Ventilation: A Manual of Recommended Practice for Design, 27th Edition. ACGIH signature publications. p. 13-45. ISBN: 978-1-607260-13-4.

British Standards Institution. (2007). PD 6699-2:2007. Nanotechnologies -Part 2: Guide to safe handling and disposal of manufactured nanomaterials. London: BSI.

Cheng YS. (2001) Condensation detection and diffusion size separation techniques. BARON P.A., WILlEKE, K. (ed.) - Aerosol Measurement, Principles, Techniques and Applications. 2ème ed. New York, Wiley Interscience, 569-601.

EN12469. (2000) Biotechnology. Performance criteria for microbiological safety cabinets. AFNOR

European Commission. (2011) COMMISSION RECOMMENDATION of 18 October 2011 on the definition of nanomaterial. Official Journal of the European Union, 2011/696/EU.

Flagan RC. (2001) Electrical Techniques , BARON P.A., WILLEKE, K. (ed.) Aerosol Measurement, Principles, Techniques and Applications. 2nd ed. New York, Wiley Interscience, 537-568.

Heim M, Kasper G, Reischl GP, Gerhart C. (2004): Performance of a New Commercial Electrical Mobility Spectrometer, Aerosol Science and Technology; 38: 3-14.

Hervé-Bazin B, et al. (2007) Les nanoparticules : Un enjeu majeur pour la santé au travail ? EDP Editions ISBN: 978-1-607260-13-4. 
INRS, ED6050. (2009) Nanomaterials: Definitions, toxicological risk, characterization of occupational exposure and prevention measures. INRS

INRS. (2012). ED6115. Nanomateriaux : Prévention des risques dans les laboratories. INRS

IRSST. (2009). Report R-599. Best practices guide to synthetic nanoparticle risk management. IRSST

ISO 14644-1. (1999) Cleanrooms and associated controlled environments - Part 1: Classification of air cleanliness. International Organization for standardization

Johnson AE, Fletcher B. (1996) The effect of operating conditions on fume cupboard containment. Safety Science; 24: 51-60.

Kim DS, Hong SB, Kim YJ, Lee KW. (2006) Deposition and coagulation of polydisperse nanoparticles by Brownian motion and turbulence. J Aero Sc; 37: 1781-1787.

Kim DS, Park SH, Song YB, Kim DH, Lee KW. (2003) Brownian coagulation of polydisperse aerosols in the transition regime. J Aero Sc; 34:, 859-868.

Koivisto AN, Yu M, Hämeri K, Seipenbusch M. (2012) Size resolved particle emission rates from an evolving indoor aerosol system. J Aero Sc; 47: 58-69.

Lee KW, Gieseke JA. (1994) Deposition of particles in turbulent pipe flows. J Aero Sc ; 25 , 699-709.

Mouret G. (2008) Thesis : Study on nanoparticles aerosol filtration. INPL - Institut National Polytechnique de Lorraine

Nicholson GP, Clark RP, De Calcina-Goff ML. (1999) Theoretical and practical comparison of the potassium iodide tracer method (KI-Discus) for assessing the containment efficiency of fume cupboards with the gas tracer method described in BS7258: 1994: Part4. Ann Occup Hyg; 43: 257-267.

Poland CA, Duffin R, Kinloch I et al. (2008) Carbon nanotubes introduced into the abdominal cavity of mice show asbestos-like pathogenicity in a pilot study. Nat Nanotech; 3: 423-428.

Prevost C, Dupoux N, Laborde JC, et al. (1997) Experimental and numerical studies of dynamic containment at a workplace. Ventilation 1997, Ottawa

Prevost C, Dupoux N, Laborde JC, (1998) Influence of the size distribution of aerosols on the containment barrier efficiency. 14th CFA 1998, Paris

Rake B W. (1978) Influence of crossdrafts on the performance of a biological Safety Cabinet, Applied and Environmental Microbiology, 278-283.

Skaptsov AS, Baklanov AM, Dubtsov SN et al. (1996) An experimental study of the thermal rebound effect of nanometer aerosol particles. J Aero Sc; 27 : 145-146.

Tsai SJ, Huang RF, Ellenbecker MJ. (2009b) Airborne nanoparticle exposures while using constant-flow, constant velocity, and air-curtain-isolated fume hoods. Ann Occup Hyg; $1-10$.

Tsai SJ, Ada E, Isaacs JA, Ellenbecker MJ. (2009a) Airborne nanoparticle exposures associated with the manual handling of nanoalumina and nanosilver in fume hoods. J Nano Res; 11 : 147-161.

Tseng LC, Huang RF, Chen CC, Chang CP. (2007a) Effects of sash movement and walk-bys on aerodynamics and contaminant leakage of laboratory fume cupboards. Industrial Health; 45: 199-208. 
Tseng LC, Huang RF, Chen CC, Chang CP. (2007b) Aerodynamics and performance verifications of test methods for laboratory fume cupboards. Ann Occup Hyg; 51: 171-183.

University of California. (2007) Nanotechnology: guidelines for safe research practices. Berkeley, CA: University of California.

Wood NB. (1981) A simple method for the calculation of turbulent deposition to smooth and rought surfaces. J Aero Sc; 12: 275-290. 